\title{
Transboundary cooperation and mechanisms for Maritime Spatial Planning implementation. SIMNORAT project
}

\author{
Gomez-Ballesteros $M^{1}{ }^{1,}$, Cervera - Núnez $C^{1}$, Campillos-Llanos $M{ }^{1}$, Quintela $A^{2}$, Sousa $L^{2}$, \\ Marques $\mathrm{M}^{2}$, Alves $\mathrm{Fl}^{2}$, Murciano $\mathrm{C}^{3}$, Alloncle $\mathrm{N}^{4}$, Sala $\mathrm{P}^{5}$, Lloret A ${ }^{3}$, Simao Ap ${ }^{6}$, Costa $\mathrm{C}^{6}$, \\ Carval Dominique ${ }^{7}$, Bailly Denis ${ }^{8}$, Nys Cecile ${ }^{7}$, Sybill $\mathrm{H}^{8}$, Dilasser $\mathrm{J}^{5}$
}

${ }^{1}$ IEO - Spanish Institute of Oceanography, Calle Corazón de María, 8, 28002 Madrid, Spain

2 CESAM - Centre for Environmental and Marine Studies \& Department of Environment and Planning, University of Aveiro, Campus de Santiago, 3810-193 Aveiro, Portugal

${ }^{3}$ CEDEX - Centro de Estudios de Puertos y Costas, Área de Medio Marino, Calle de Antonio López, 81, 28026 Madrid, Spain

${ }^{4}$ AFB - Agence Française pour la Biodiversité, Site de Brest, 16 Quai de la douane, France

${ }^{5}$ CEREMA - Centre d'études et d'expertise sur les risques, l'environnement, la mobilité et l'aménagement, France

${ }^{6}$ DGRM - Direção-Geral de Recursos Naturais, Segurança e Serviços Marítimos, Avenida Brasília, 1449-030 Lisboa, Portugal

7 SHOM - Service Hydrographique et Océanographique de la Marine, 13 rue du Chatellier, 29200 Brest, France

8 UBO, Université de Bretagne Occidentale, UMR 6308 Amure, France

*Corresponding author : M. Gomez-Ballesteros, email address : maria.gomez@ieo.es

\begin{abstract}
:
Maritime Spatial Planning (MSP) is gaining importance as a new process for the governance of seas and oceans, as maritime nations exercise greater management over their territorial waters and, in many cases, over exclusive economic zones that span a larger area. The purpose of this planning is to reverse the environmental degradation of the seas and facilitate the sustainable use of marine resources, both for mature uses such as fishing and navigation, and for emergent uses, including renewable energies and mariculture. In Europe, the Directive 2014/89/EU of the European Parliament and of the Council of 23 July 2014 establishing a framework for maritime spatial planning oblige coastal Member States to develop maritime spatial plans at the latest by 31st March 2021. To help in that process, countries have at their disposal a set of existing instruments, including research projects, supporting guidelines, recommendations and sets of tools and data, as the SIMNORAT project, co-funded by the EC - DG Maritime Affairs and Fisheries (DG MARE). This paper presents best practices developed in this project on technical, scientific, and social aspects of MSP to overcome barriers of MSPD implementation testing effective cooperation on transboundary areas and providing a set of cross-cutting MSP related recommendations to foster collaborative efforts and to improve the overall transboundary dimension of the MSP Directive.
\end{abstract}

Keywords : Marine Spatial Planning, Cross-border cooperation, Stakeholders, Transboundary effects, SIMNORAT project 

adopt a definition of clear rules for access to resources and spaces, and consider the environmental, social and economic aspects of the planning process ${ }^{1,2,3}$. Increasing the demand of marine resources and development of human activities in the marine realm is resulting in more pressures on the ecosystems and competition and conflicts between marine users, therefore, new management models are needed. Identification of synergies, transnational coordination and coordinated actions are fundamental to progress towards an efficient Maritime Spatial Planning (MSP) management approach in order to solve conflicts and promote multiple uses and activities. On the other hand, ecosystem-based management (EBM) is an approach "based on a particular area defined by the location of a given ecosystem"4, highlighted as an important underlying principle to plan maritime space. MSP can balance maritime activities and foster crossborder cooperation while developing a new scheme of multilevel governance, defining and applying legislation and coordination between the different administrative levels of management. As MSP analyses and allocates the spatial and temporal distribution of human activities at sea, it is a fundamental tool towards the sustainable management of marine resources.

The EU Directive (MSPD) 3 establishing a framework on MSP was adopted in 2014 and according to article 1 , it aims to promote the sustainable growth of maritime economies, the sustainable development of marine areas and the sustainable use of marine resources giving the sole responsibility to Member States (MS) of implementing maritime spatial plans ${ }^{5}$. Accordingly, MS have to design and prepare the format and content of the MSP plan and identify the distribution of current and future activities and uses in their marine waters taking into account their interactions. Related to article 4, MSP should be "built upon existing national, regional and local rules and 
mechanisms", also ensuring a public participatory process as well as cooperation between MS but also with Third Countries as established in article 6. According to the MSP Directive, MS shall ensure the involvement of stakeholders throughout the entire process, from the initial definition of objectives to the concession of access to the plans once they are finalized. To ensure that MSP is based on reliable data and to avoid additional administrative burdens, it is essential that the MS rely on the best available data and information by encouraging stakeholders to share information and using instruments and tools for data collection in order to identify spatial demands and future trends in the maritime sectors. Furthermore, in consonance with article 10 of the Directive, MS must organize the use of the best available data and the sharing of information, necessary for maritime spatial plans. Data used may include environmental, social and economic data related to activities and uses, and marine physical data about marine waters. Moreover, MS shall make use of relevant instruments and tools, including those already available under the Integrated Maritime Policy, for example, EMODnet data portals ${ }^{34}$, and under other relevant EU policies, such as those mentioned in the Inspire Directive 2007/2/EC ${ }^{35}$.

In this respect, the European Commission through the Directorate-General for Maritime Affairs and Fisheries (DG MARE) co-funded the project "Supporting Implementation of Maritime Spatial Planning in the Northern European Atlantic region (SIMNORAT)"7 aimed to support the implementation of the MSPD ${ }^{3}$ establishing a framework for MSP in the European North-Atlantic waters, and to establish a concrete cross-border MSP cooperation between countries involved. The project area of interest corresponds to the jurisdictional waters of Portugal, Spain, and France of the OSPAR Region IV and was extended to cover the Vigo and Vasco da Gama seamounts and the Galician Bank (Fig. 1). The project brought together several partners, composed by research organizations, maritime planning authorities and management bodies from France, Portugal and Spain.

In order to achieve the ambitious objectives stated above, several tasks were designed to develop methodologies and good practices and to test specific aspects that could contribute to a potential MSP process in selected cross-border areas defined as case studies. 


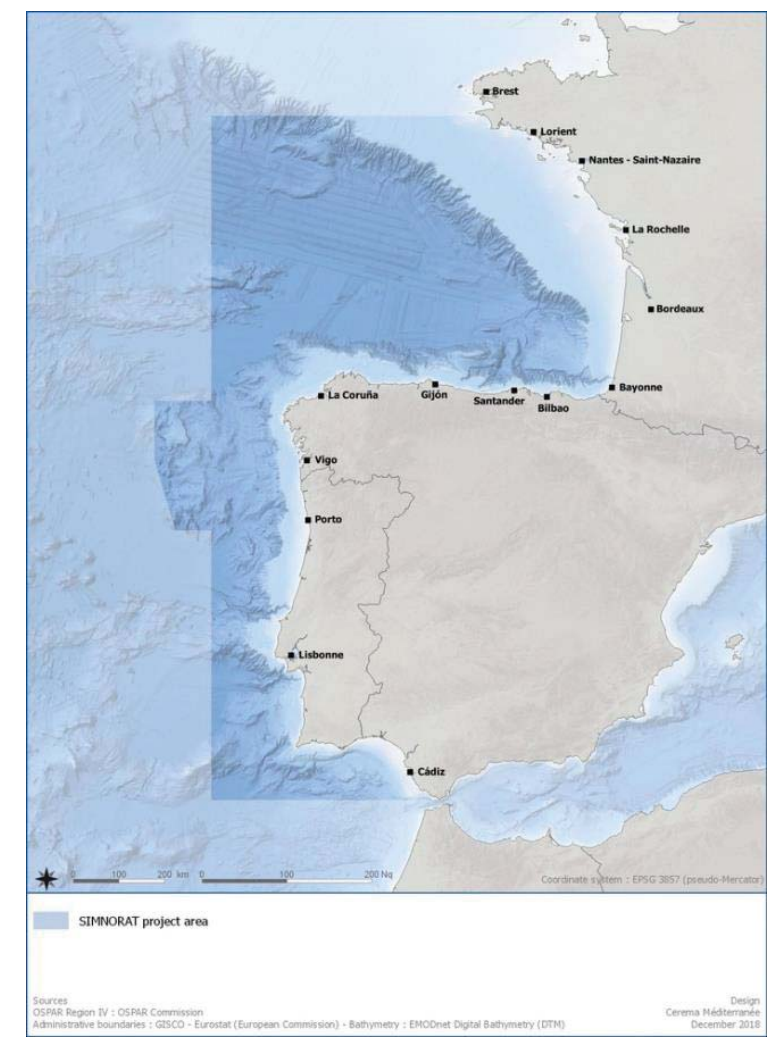

Figure 1 - SIMNORAT project area ${ }^{8}$.

\subsection{Maritime Spatial Planning Processes in Spain, Portugal and France: MSP State of play}

MSP aims at attributing maritime space to uses while reducing conflicts, strengthening cross-sectorial cooperation and following an ecosystem-based approach "to achieve ecological, economic and social objectives" ${ }^{3}$. MS have the sole responsibility of transposing the Directive into their national legislation, setting up a competent authority in charge of implementing MSP. SIMNORAT project supports the associated process in Spain, Portugal and France, countries in different stages of their national MSP implementation and following different approaches.

- MSP implementation process in France: The EU MSP Directive was transposed into the French legislative system by the Order 2016-1687 of 8 December 2016. The Ministry for the Solidarity and Ecological Transition (MSET) is the national authority responsible for its implementation, which will be divided into four sea basins and four Interregional Directorate for the Sea, respectively dealing with Eastern channel and North Sea; Northern Atlantic; Southern Atlantic and Mediterranean Sea (SFPD) basins. The law indicates the Strategic Façade Planning Documents as the main tools for MSP implementation, under the authority of a couple of regional and maritime Coordinating Prefects. These documents unite strategically Marine Strategy Framework Directive (MSFD) and MSPD implementations. Currently, SFPD are being reviewed nationally and internationally to be edited. The strategic part of the astern channel and North 
Sea and Northern Atlantic SFPD has been approved by inter-prefectoral orders in the September 2019.

MSP implementation process in Spain: In Spain, the Royal Decree 363/2017 of the 8 April established a national framework for MSP. Besides, the Spanish Law $41 / 2010$ put down the principles for planning the marine environment through the implementation of Marine Strategies. The national authority in charge of MSP is the Ministry for the Ecological Transition and Demographic Challenge (MTERD), General Directorate of the Coast and the Sea. It will develop Strategic Documents for five areas of planning: Northern Atlantic; Southern Atlantic; Canary basin; Strait and Alboran; Levantine and Balearic. The Law 41/2010 created the Interministerial Commission of Marine Strategies under which was created the MSP-Working Group for the MSP national process. Moreover, the knowledge and data to be used in the Maritime Spatial Plans will be produced by the research conducted under the Marine Strategies program. Till date, no Maritime Spatial Plans have been approved or implemented in Spain, however a first draft of the 5 plans have been launched for public consultation in the framework of the Strategic Environmental Assessment (SEA) required by the Directive 2001/42/EC of the European Parliament and of the Council of 27 June 2001 on the assessment of the effects of certain plans and programmes on the environment.

- MSP implementation process in Portugal: Portugal started by developing its National Strategy in 2008 and released its Plano de Ordenamento do Espaco Maritimo (POEM) in relation to MSP, initiated by Ruling No.32277/2008. Portugal is following its National Ocean Strategy 2013-2020 targeting a sustainable development of the economic sectors related to the ocean, and giving Portugal the opportunity to pursue promotion and increase growth and competitiveness in its maritime economy. The Portuguese MSP fundamental Law No. 17/2014 on maritime spatial planning and management was approved in April 2014 and was enabled in legislation through the Decree-Law no 38/2015, in March 2015. The Ruling no 11494/2015 established the beginning of the preparation and development of the Situation Plan (PSOEM) in 2015, currently commits the elaboration of the plan to the Directorate General for Natural Resources, Safety and Maritime Services (DGRM) in the Mainland and Extended Continental Shelf subdivisions. For the two autonomous islands, the competent authorities are the Sea Regional Directorate (DRM) of the Madeira Regional Government and the Regional Directorate for Maritime Affairs (DRAM) of the Azores Regional Government. The plan for the Mainland, Madeira and extended continental shelf was approved in December 2019 by the Resolution of the Council of Ministers $n=203-A(2019)^{9}$.

\subsection{Major Steps for transboundary cooperation: Overwiev of MSP directive implementation process with special focus vertical and horizontal coordination.}


According to the description presented in the previous section, we can resume that MSFD and MSPD implementations are somewhat related in the three countries of the project. The monitoring action plan of the formal process of MSP in Portugal, regarding ecologic and biologic issues is based on the MSFD implementation process. In Spain, the MSP process is aligned with MSFD as in France, where a strategic document has been developed joining both processes for each planning subdivisions. In two of the three MS the same national competent authority is responsible for the implementation of the four EU directives: MSFD, MSPD, and Conservation of Natural Habitats and of Wild Fauna and Flora Directive (Habitats Directive - $H D^{10}$ ) and the Conservation of Wild Birds Directive (Birds Directive - BD).

Regarding another kind of coordination, it is necessary to undertake an analysis focusing in the expectations and positions of regional authorities in relation to MSP as they can be key actors for a successful implementation of this Directive at local and cross-border areas. Apart from coherence and coordination with sectorial policies (i.e. MSFD-MSP) there must be coordination and collaboration between the different levels of governance, local, regional and national to ensure compliance with the Directives. This is the case of the management of coastal waters, where the greatest development of maritime uses and activities is gathered in the first nautical miles, concentrating the major source of conflicts in a relatively small space. It is, therefore, necessary to address these issues in coordination with regional and local authorities, depending on their competences and regulatory powers, and based on the framework established by national competent authorities. Moreover, consideration of the land-sea interface in planning processes must be integrated by ensuring a continuum between planning exercises on land and at sea. The role of regional authorities is therefore important, as, in addition to exercising their regulatory powers, they play a role in seeking consensus between local stakeholders concerning the definition of areas for the development of certain activities.

These same issues may arise in cross-border areas, where each state may have different objectives. Conflicting interests should be identified in a MSP process in terms of potential transboundary issues to describe sensitive areas. Regional authorities in these cases can also be facilitators in creating links with other stakeholders and actors in the field of transboundary implementation of the MSDF, MSP, Birds and Habitats Directives.

\section{Objectives}

The mission of SIMNORAT project was never to build a plan for the entire area of the project but to develop and test aspects of the MSP process in order to produces useful guidelines and recommendations for MSP Competent Authorities of the countries involved. SIMNORAT project objectives are practitioner focused, and look to identify and share best practice on technical (e.g. data management), scientific (e.g. EBM), and social (e.g. stakeholder engagement processes) aspects of MSP implementation to overcome barriers of the MSP Directive implementation and effective cooperation on transboundary areas. To address these objectives, several methodological approaches 
have been developed to focus on conflicts and synergies identification, future trend analysis and stakeholder engagement mechanisms, through the development of different tasks and case studies:

- Literature review on the most appropriate geographical scale for MSP at national level.

- Analysis of the integration of Marine Protected Areas (MPAs) in the context of MSP.

- Analysis of data needs and existing gaps and the development of a data management methodology.

- The role of the regions in MSP.

- The definition and application of MSP by the OSPAR convention.

- Coordination of sectorial policies.

- Stakeholder perception on Maritime Spatial Planning.

- Spatial demands and future trends for maritime sectors.

- Bay of Biscay case study - Mapping exposure risk of marine megafauna to concomitant pressures.

- Crossborder MPA Galicia Bank - Vigo and Vasco da Gama seamounts. The development of these activities allowed the definition of common operative tools, as common system for storing, visualizing and managing geographical data, an analysis of uses and activities spatial demands focused on the way that sectors are organized; the identification of key stakeholders and testing of participative mechanisms; the definition of case study areas, boundaries and scale, ensuring connectivity between ecosystems accordingly to the EBM approach.

- Develop and propose a conceptual methodology for transboundary MSP in the Northern Atlantic.

The tasks mentioned above were carried out to achieve the objectives of the project, but not all of them will be addressed in this paper, which focuses only on those most relevant to explain the conclusions derived for the application of the Transboundary cooperation and mechanisms for Maritime Spatial Planning implementation.

\section{Material and methods}

The complexity and scope of the application of the MSP Directive leads the MS to establish, according to their governance system and their objectives, appropriate methodologies for designing their planning and stakeholders consultation processes. This section presents the methodological framework and key elements developed in the project.

\subsection{Conceptual methodology for transboundary MSP from Literature Review}

The transboundary cooperation required to achieve coherence among MSP processes in each sea basin is crucial but also a challenging mission. The first step in the project 
was to design a conceptual framework to examine the methodological aspects of the ongoing MSP processes of the countries and to discuss the major barriers and bottlenecks when addressing the operationalization of MSP Directive principles and guidelines, specifically at transboundary level.

Accordingly to the literature review ${ }^{11,12,13,14,15,16}$ and case studies in other projects (such as TPEA $^{17}$, BaltSeaPlan ${ }^{18}$, MASPNOSE $^{19}$ and ADRIPLAN ${ }^{20}$ ), major steps in MSP process were classified linked to the ecosystem based approach (EBA) in a transboundary context: Pre-planning; Analysis; Planning; Implementation; Monitoring; Evaluation; and Stakeholder engagement and Communication throughout the entire process (Fig. 2).

A SWOT analysis was undertaken to identify the strengths, weaknesses, opportunities and threats, which was based ${ }^{21}$ for each step defined having in consideration the visions of each of the partner's countries. The results of the SWOT analysis are delivered in the Discussion section.

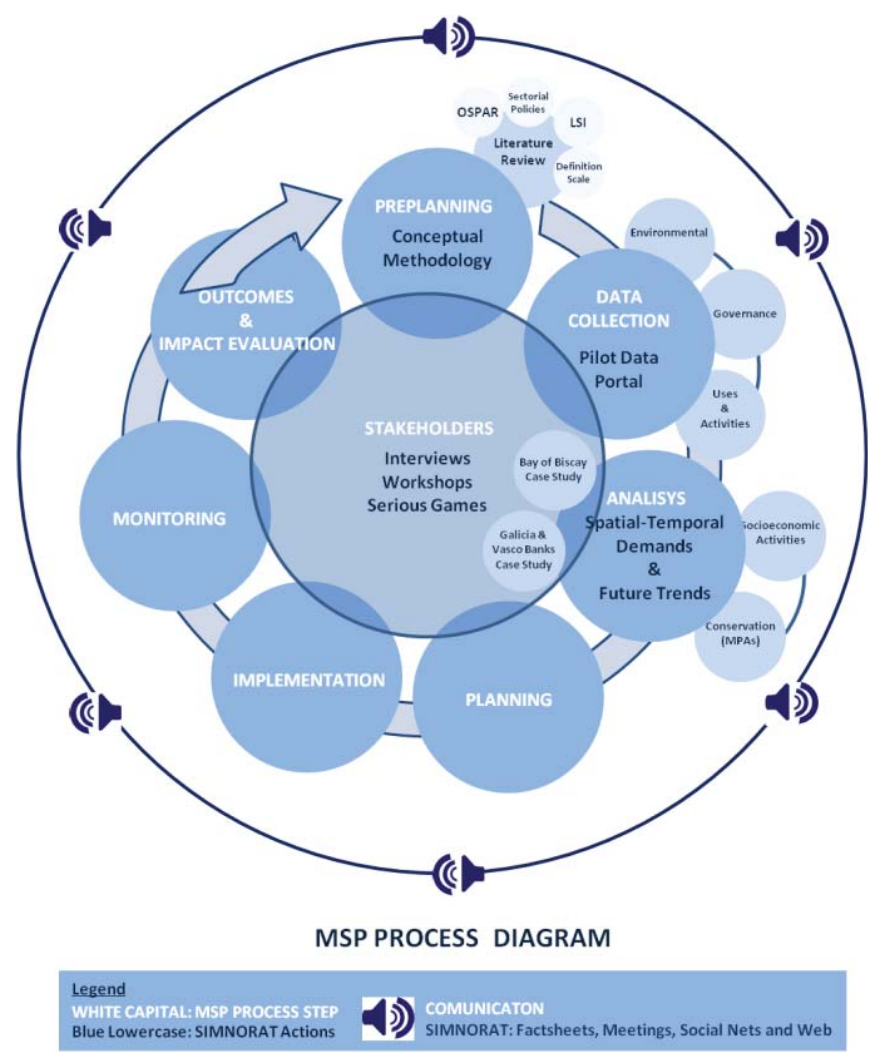

Figure 2. The MSP process diagram defined in the context of SIMNORAT project, after reviewing the ones seven different steps of MSP, and the actions carried out.

Agreeing this classification, the project planning was designed considering the objectives postulated. The white capital letter in figure 2 corresponds to the MSP process steps classification, but during SIMNORAT project only some of them could be carried out due to the objectives of the project did not include developing a plan or subsequent steps in a whole process. So, in order to be coherent with the objectives just the three first steps (blue lowercase in figure 2) were overcome to produce useful 
guidelines and recommendations on technical, scientific and social aspects for MSP, especially in a transboundary context. In this sense, figure 2 represents the project workflow agree by the seven MSP steps and the different tasks accomplished during the project related with each step (also blue lowercase). The project results dissemination is an important aspect to reach a larger interested public, not only at the level of the countries involved in the project but also for the entire international MSP community, to share the experiences and lessons learned. Therefore, as an MSP process must be open and participatory throughout its development, during the project this communication has also been maintained through factsheets, meetings, web, and social nets.

Besides from analyzing the process itself at transboundary level, some other issues were approached at national level (i.e. to define the most appropriate scale), international level (i.e. OSPAR), sectorial (i.e. different policies and governance frameworks) and local (i.e. land-sea interactions).

To implement MSP it is necessary to define the scale of the process, however, this is not defined by the Directive and has been approached differently by each country, having even opted for a combination of different scales: national, regional and local. But, what is the most appropriate scale for their MSP plans? Do they have to define different plans based on different geographical scales? If so, what would be their articulation? If not, for instance, is it enough to carry out the plan at national or marine basin scale with some focus areas? Moreover, what would be the plan boundaries once the scale is defined? Defining the most appropriate geographic scale involves taking into account differences that may exist between ecosystem scales and existing governance, social and economic scales ${ }^{30}$. Furthermore, this will affect the actions carried out in the plan at different stages of the process such as defining objectives, involving stakeholders, identifying demands for space and conflicts, as well as the vulnerability of the spaces in question ${ }^{31,32,33}$. Therefore, in the literature review phase, an analysis of the previously existing information on this concept was carried out, to suggest principles to follow in scaling the plan, defining its boundaries and the number of plans to develop within a country, always taking into account transboundary issues.

Considering that one of the objectives of the project is the transboundary cooperation in the north Atlantic region, it is important to mention the convention for the Protection of the Marine Environment of North-East Atlantic, or OSPAR Convention ${ }^{22}$. This does not explicitly refer to MSP, however, it calls for the need for protection of marine areas through appropriate programs and sets out common objectives and principles to which the Member States must adhere. OSPAR represents an important platform to encourage and enhance transboundary MSP due to the dynamic collaboration between Contracting Parties and the transboundary nature of the marine resources and activities. Although it does not have a direct role on MSP implementation neither a legal framework, it intends to develop appropriate measures, as guiding principles, in line with the Ecosystem Approach and to facilitate MSP in the OSPAR maritime area, taking into account the cooperation in transboundary issues arising from MSP. Additionally, it could serve as a mechanism for early transnational consultations on MSP providing region specific, tailored-made 
approaches to applying MSP to support Ecosystem Approach and to exchange of best practices and experiences regarding MSP.

The coordination of sectorial policies is also essential in MSP processes. The relevant sectorial policy instruments regarding MSP implementation process are key to guaranty the successfulness of the process according to national and regional obligations and policies, and the several policy instruments of the legal framework for MSP, namely the United Nations Convention on the Law of the Sea (UNCLOS ${ }^{23}$ ), the Convention on Biological Diversity $\left(\mathrm{CBD}^{24}\right)$ and the Espoo Convention on Environmental Impact Assessment in a Transboundary Context (Espoo EIA ${ }^{25}$ ). Therefore is imperative to enhance the integration between all existing marine policies contributing to the improvement of the coherence among countries promoting regional knowledge exchange; coordination between and among stakeholders responsible for the implementation of policies; vertical and horizontal cooperation among administrations, technical agencies, and stakeholders and knowledge of the implications and requirements for the various sectorial policies regarding MSP.

To ensure that maritime activities can deliver growth and avoid sea-use conflicts, integrated planning of human activities both on land and at sea is needed. Most development and use, which takes place in the marine environment also has an onshore component or impact. Planners on MSP have to consider land-sea interactions (LSI) when establishing and implementing the plans, to promote an integrated and strategic vision for MSP that is coherent with land use planning frameworks and highly related to the economic benefits of MSP and the importance of given maritime uses covered by the MSP for the economic development of the region in question. The need for an integrated and strategic approach to the management of the coastal zone is evident to achieve the goals not only of the MSPD but also related to others European processes such as the Integrated Coastal Zone Management (ICZMError! Bookmark not defined.,26) recommendation, the MSFD27, and the Water Framework Directive (WFD28).

Regarding water-related issues, the WFD and the MSFD, as illustrated in figure 3 , these two directives and the MSPD may overlap in coastal waters, requiring articulation among institutions and coherence between methods and processes.

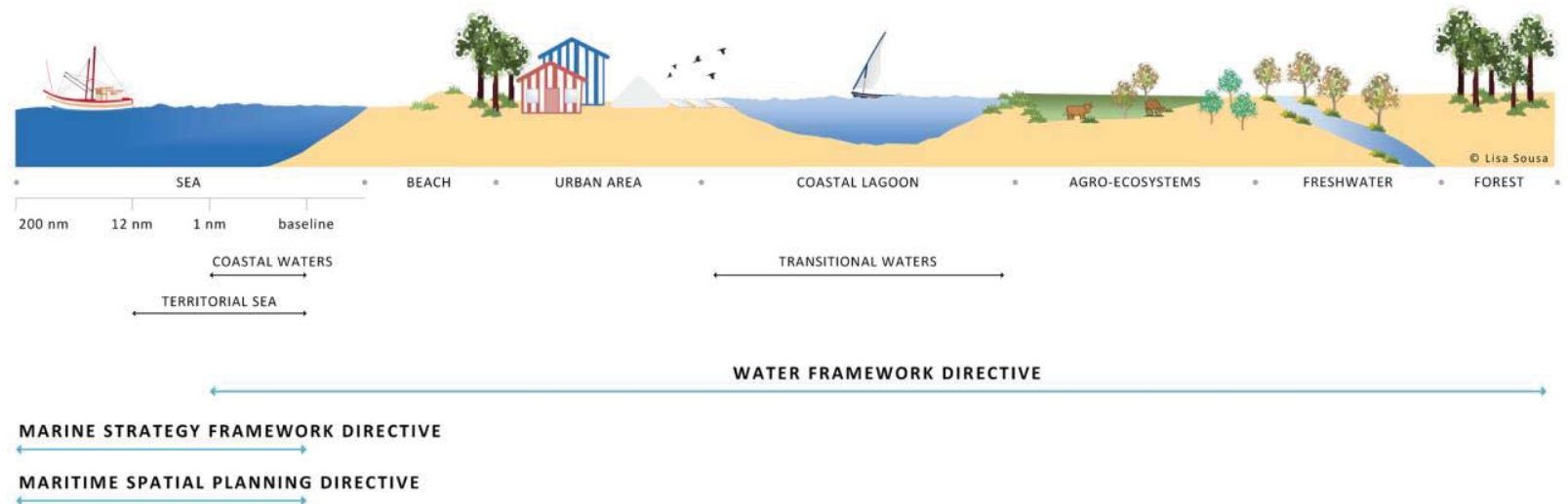

Figure 3. Spatial incidence of MSFD and WFD ${ }^{29}$. 
In the scope of SIMNORAT project, land-sea interaction has been studied as a complex phenomenon relating to the natural processes across the land-sea interface, the interactions between uses and activities at the sea and the land, but also to their impacts and pressures on the quality or ecological dynamics of coastal and marine environments and the governance arrangements in these interface and socioecological systems. But nevertheless, it has not been a component approached during its development with the same intensity as other tasks.

\subsection{Data collection and information requirements for MSP}

Data use and sharing is required to implement the MSPD. In particular, to fulfil the requirement of coherence of MSP plans along sea basins, data and information sharing should be approached at transboundary level, to take into account issues of transnational nature.

Data collection and information requirements for MSP have been another aspect of the MSP process studied on SIMNORAT project. The work has focused on a technical study aiming to support access to and use of maritime spatial data in France, Portugal and Spain at regional level and has been organized differently depending on the initial, middle or final state of the project, to address the requirements of each phase. In general, it has been focused on data exchanges aspects using a Maritime Spatial Data Infrastructure and INSPIRE protocols regarding interoperability of data, metadata, data portals and Web Services.

Initially, a review of the available public and institutional data portals with relevant information in the North Atlantic basin along the maritime territories of the three involved countries was undertaken. From the data collected, an inventory of the relevant available data for MSP in the North Atlantic basin was prepared, processed and stored in a data portal.

The data themes selected were governance (limits of jurisdictional waters, regulations at international, national, regional and local levels, etc.), environmental data (characterization and pressures, etc.) and human activities (uses and activities, conflicts, pressures, etc.). Finally, a pilot interoperable data portal was developed with all information and data compiled as web map services (WMS) to achieve the objective of facilitate interoperability of data. To conclude, an analysis of the processing and management of the data and technical aspects were carried out.

\subsection{Spatial demands and future trends identification}

MSP is a necessary tool to regulate pressures arising from activities trends, maintain or improve the good state of the marine environment and to ensure the prevention and management of conflicts between uses (existing or potential). This includes analyzing the spatial consequences of future trends in each sector and defining specific and 
achievable development objectives, to define a complete projection of the spatial ambitions of a given sector. The protection of marine biodiversity and the different categories of MPAs could be addressed also through the MSP processes and could enter into competition for space with the maritime activities. The specific objective of this component is to investigate current and future demands of maritime sectors, with specific reference to cross-border issues, identifying the capacities of the sectors to organize themselves and to express their demands reflecting on current and future trends, including marine conservation. The research work carried out in the project is a combination of bibliographic analysis and the capitalization of interviews carried out through the activity on stakeholder engagement of the project:

- Desk analysis was conducted for each of the eight sectors (Fisheries; Aquaculture and fish farming; Commercial transport and ports; Marine renewable energies; Aggregate extraction; Gas and oil; Yachting and recreational activities; Underwater cables) and at the level of the 3 member states, focused mainly on the expected evolution of each sector, the interaction among and between sectors and the environment and to characterize the expression of spatial needs by representatives of the sector. Regarding MPA polices, a review to describe the management processes was carried out, and an update of the North East Atlantic MPA database ${ }^{37}$, developed by a previous Interreg Project (MAIA Project - Marine protected areas in the Atlantic $\operatorname{arc}^{38}$, for the 350 MPAs of the SIMNORAT project area).

- Interviews were realized to sectors representatives, in order to obtain information regarding sectorial identification of spatial demands, including questions related to activity evolution trends. A total of forty-four anonymized interviews were carried out by the project partners, out of which, twenty-three were in France, thirteen in Portugal and eight in Spain. Twenty-five of these interviews with representatives of fishing, shipping, industry and boating activities were used for this task.

A synthesis of the work was produced with the results of the desk analysis and the interviews, adding the legal, political and technical components that can influence the spatial demand of a sector.

\subsection{Stakeholders engagement}

The objective of this component was to explore good practices mechanisms on a transboundary context testing different methods of engagement beyond formal processes to promote discussions among stakeholders. Finally, to raise awareness regarding MSP and to communicate the outcomes of stakeholder's engagement component an informative document with the main results of this component was produced. The three main methods of stakeholder engagement used in this project, tested in at least one of the three countries, were:

- Interviews (FR, SP, and PT) settled in order to collect the stakeholders' sectorial visions and the MSP process expectations in their countries. The sample was 
composed of maritime sectorial representatives, MPA managers and conservation NGOs previously identified and contacted personally. The method used was the semi-structured interview, combining a pre-determined set of open questions with the opportunity for the interviewer to explore more deeply some particular themes or responses, allowing stakeholders to express themselves freely.

- Participatory Workshops (FR, SP, and PT) 2 types of workshops were carried out, the cross-border workshops, conducted between France and Spain - and Spain and Portugal; and the national workshop only conducted in France. During the workshops, different sessions of participation were organized including post-it sessions and mapping discussions. Stakeholders were organized in groups representing different sectorial objectives in order to identify conflicts, synergies, gaps of knowledge or to answer specific questions. Results were shared in a plenary session. This type of workshop is generally used to promote discussions between different levels of expertise in order to propose solutions to conflicts and to share knowledge and points of view between stakeholders.

- Serious games (FR), The "MSP - Blue Development Edition" board game, commonly known as "MSP Challenge", is a strategic board game developed at the request of the Ministry of Infrastructure and Water Management of the Kingdom of Netherlands. It is designed for policy-makers and stakeholders with an interest in the field of $\mathrm{MSP}^{39,40,41}$. This "serious game" allows for a better understanding development process about the issues involved in MSP through creative and imaginative role-playing. It was played only with French stakeholders and 21 participants from different sectors of maritime activities, administration and environment managers who played the game adapted to the SIMNORAT project objectives.

\section{Analysis and Results}

\subsection{Conceptual Methodology for a Transboundary EBM-MSP: The importance of scales}

The EU Directives3,10,27 together with platforms and regional authorities, foster the cooperation with stakeholders, both at nationally and internationally level, but the existing differences in application and timing present a handicap.

To tackle measures at local level, especially those related to sectorial regulation with respect to conservation and protected areas, regional and local authorities are key actors in facilitating the awareness of citizens and reaching out stakeholders in their territories, through communication channels and active participation of civil society. This is especially important in the land-sea interface, where there still seems to be a lack of connection between MSP, land planning and ICZM, where a practical approach and articulation between them is a need ${ }^{42}$. It is therefore evident that coordinating 
planning on land and at sea makes it possible to optimize the implementation of infrastructures and services on the land required for activities at sea and vice versa.

According to the Directive, MSP is a MS competence, so it will be applicable at a national (sub-national and local) scale, but it has to be based on an ecosystem approach, which has a wider scale (bioregional). Therefore, a mismatch between ecological and administrative boundaries might arise. Since we understand scale as a jurisdictional ${ }^{43}$, ecological ${ }^{44}$ and socio-economic levelError! Bookmark not defined. of the MSP process and its components (sub-process, activity and phenomenon), in space and time, the relationship between scales and scale interactions is a hierarchical concept ${ }^{40}$. It is therefore acknowledged that in a sound MSP process it is necessary to differentiate between different scales.

The literature stresses that in the delineation of an area for the development of MSP, a relative consensus seems to exist on the difference between two types of boundaries: the analysis boundaries and the management boundaries ${ }^{17,32,45,46}$. The argument for this distinction is that the management boundaries often match administrative boundaries (for political purposes), which do not generally correspond to the boundaries of a single ecosystem ${ }^{16}$. This is also supported by the consensus in favour of the ecosystem approach, which provides a solid foundation in MSP process1,33,46,47,48. Analyzing phenomena whether environmental or socio-economic only within the administrative boundaries leads to misunderstanding of these phenomena in as much as the latter could be broader. This could lead to the failure of the plan, as a consequence of a mismatch between the ecological scale and the social/management scale ${ }^{30}$. This is why boundaries of analysis should not be limited to boundaries of management. Similarly, this is also evident in transboundary areas, where the nature of oceanic processes, marine resources, maritime activities and their impacts, exceed administrative borders. For this reason, effective planning and management require a collaborative approach from neighbouring jurisdictions1. The European projects, as SIMNORAT, are a fora to share methodologies and capacitation, and assist the application of the appropriate scale of analysis in transboundary areas ${ }^{49}$ as the definition of study areas are not limited by jurisdictional borders and governance of one country

\subsection{Data and information requirements for MSP: Analysis of data needs and gaps}

In a MSP process, spatial information is essential, both for the environmental characterization of the area and for representing the extent of uses and activities being developed. Without this information, it would be impossible to carry out risks analyses or conflicts, threats and synergies identification and lack of information. Tools have been developed that allow this type of analysis and modelling, both at the sea basin level and in hot spot areas, all depending on the spatial resolution of the information. Besides, it is necessary to have the governance component to define possible scenarios taking into account the various existing regulations at international, national, regional and local levels. Therefore, information needs to be mapped and georeferenced in order to be taken into consideration in the development of scenarios. Before starting a 
massive data collection, it is important to have identified the most relevant data to address the MSP process to prioritize and manage efforts.

In general terms, without going into details of each of the three countries, since it is not the objective of this study to explain this highly technical work, the main problems identified when compiling the existing spatial information from the different national and regional data portals or databases is the non-harmonization of information and the lack of interoperability. The information needs to be not only comparable but spatially continuous to be useful for analyses. It makes also the analysis of transboundary data very time consuming. Another challenge identified related to the access to certain sensitive information from some sectors, both at private and public environments. This issue is particularly relevant in cross-border areas, where each country establishes its standards in those data sets outside the framework of INSPIRE. As a first step after compiling all the available information was to establish a data model and organize it in a common database classifying it according to the different thematic cartography related to MSP, and its associated metadata, implementing the INSPIRE guidelines to ensure interoperability between databases. In this way, the project has developed the SIMNORAT Data Portal ${ }^{51}$ (SDP) to share and exchange spatial data for the project area, compiling a relevant spatial data for MSP from the three involved countries, targeting both, general stakeholders and policy-makers. The MSP Directive indicates the kind of data may be used for maritime spatial plans elaboration, but no established classification of data of reference exists. Nevertheless, in 2016, a MSP data study ${ }^{50}$ established a detailed categorization of MSP data related used by MS. Using this study as the basis, the initial inventory of gathered data was organized as:

- Administrative boundaries (terrestrial and maritime boundaries).

- Physical, chemical, biological information (physical characteristics, type of habitat, biological characteristics, pressures and impacts).

- Spatial policy (spatial policy, land use).

- Activities/uses (aquaculture, fishing, marine renewable energies, installations and infrastructures, maritime transport routes and traffic flows, ports, nature and species conservation and protected areas, military, raw material extraction, scientific research, submarine cable and pipeline).

\section{Data distribution by category}
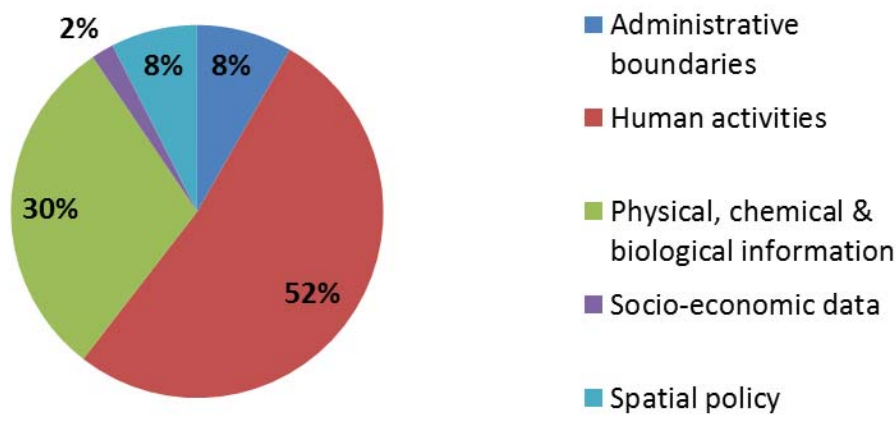
An important imbalance is evident between categories. The Human activities category gathers half of the selected datasets. Only five layers have been found in the Socioeconomic data category probably because normally this data refers to alphanumeric information with no spatial representation (Fig.5).

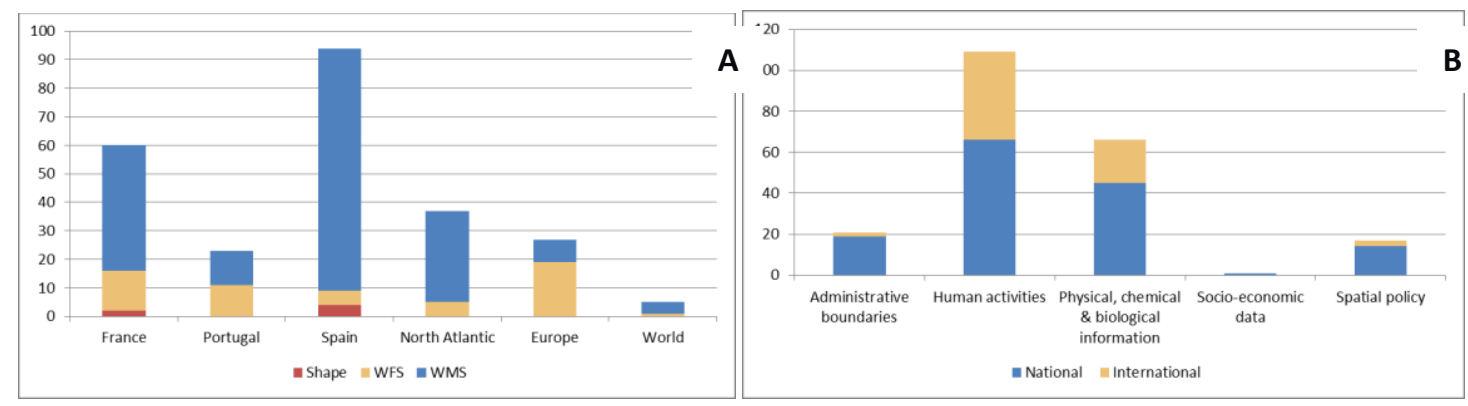

Figure 5: (A) Data format distribution by area and format. (B) Data distribution by category and by geographic level. The North Atlantic category contains data covering all or part of the study area and may concern more than one country.

The figure 5 shows that in the inventory lots of datasets are available in Web Services but also that some particularly relevant data are available only in shapefile format and the most represented format is the WMS that provides only a visualization of the spatial data. The low number of local datasets presented in this inventory is due to the selection of datasets covering the whole area to provide an overview. Local datasets can be of course useful for particular and local MSP implementation, depending on the defined scale specifically at local hot points, but their identification and collection remain difficult because they are available from different sources and they are not centralized.

As part of this analysis, a number of measures addressing data needs and gaps have been identified in order to improve MSP data sharing among countries. Some of them depend mainly on the data producers and on the cooperation framework. The resulting recommendations are gathered in an Action Plan (Table 1) and they are focused on improving the portrayal, interoperability of metadata and Web Services.

Table 1. SIMNORAT Action plan

\begin{tabular}{|ll|}
\multicolumn{1}{|c|}{ OBJECTIVE } & \multicolumn{1}{c|}{ ACTIONS } \\
\hline & - Create or complete metadata (MD) record in accordance with \\
Improve metadata & INSPIRE directive \\
and data & - Publish MD records using CSW catalogues \\
interoperability & - Produce metadata and data in several languages (give priority to \\
& English) \\
\hline
\end{tabular}


The goal of the SDP was to provide an effective tool displaying continuous spatial information of the transboundary area for stakeholders and planners facilitating the decision-making process. To evaluate the functionality of the portal, it was launched open for stakeholders to test it. Additionally, GIS experts or data experts were invited to experiment datasets interoperability and to address needs and gaps and possible solutions to overcome them in support of the "Data and Information Requirements for MSP".

\subsection{Analysis of spatial and temporal demands and future trends of socioeconomic activities and conservation}

As mentioned in the methodology section, the results of a bibliographic research were enriched by the analysis of interviews and workshops run during the project in the framework of the stakeholder engagement component.

Therefore, special consideration was given to analyze possible future trends in the maritime sectors, including changes in their growth, technological breakthroughs and interactions / competition with other activities. But this is not always easy, because many sectors do not even have a defined strategy for the future or even a clear internal organization. When talking about cross-border areas, where there are differences, not only between different sectors but even between countries, this is even more complicated. These differences may be reflected in the institutional structures of the countries, for instance, Portugal and France have a Ministry or Secretary of State for the Sea, where the competences and strategies are well defined, while in Spain they are shared between different ministries presenting different objectives and approaches.

Regarding conservation, in SIMNORAT project area, over 30 different MPA categories have been identified, coming from international, European or national regulations. MPA landscape is therefore complex since each of these categories could have different objectives (from strict conservation to sustainable development), 
management processes and regulations, management body and different levels of stakeholders involved. All these factors shall be considered together with the application of the EBM in MSP, by adapting the essential features of the planning process, and through environmental and economic impact assessments.

The interest in this analysis during the project was in the direct expression of the spatial demand by the representatives of the activity. This expression reflects the concrete vision, specific to each sector, of its evolution as well as its expectations regarding MSP. The purpose of this study is not to define and study several prospective development scenarios or to map sectorial trends, but rather to explore the factors influencing its development (policies, interactions, context, etc.) and to characterize positioning strategies related to MSP. In this analysis, the common variables likely to constitute a priori factors influencing the expression of the spatial demand have been identified for the three Member States. A common analysis grid of the expression of space demand has therefore been developed for the following 8 maritime sectors:

- Aquaculture

- Fisheries

- Cables and Pipelines

- Offshore Wind Energy

- Ports and Shipping

- Yachting

- $\quad$ Oil and Gas

- Marine renewable energy

In the analysis grid created for this study, three rubrics should make possible to bring contextual elements and to account for the spatial demand expressed by the representatives of each sector:

1) The structure of the sector and channels of expression to analyze, for each maritime sector, the structuring, its organization and its level of participation in the process of MSP in order to understand the channels of expression that presents for claiming "spatial demand".

2) The analysis of the sector in its environment, taking into account interactions with other activities and marine conservation. This part aims at understanding and analyzing the weight of the activities interactions with its environment in the characterization of the spatial demand. Three types of interactions are thus studied as possible factors influencing the spatial demand: interactions between activities, between different sectors or inside the same sector (for example: different fishing practices); interactions between activities and environmental values regarding constraints felt by the parties concerned with respect to environmental regulations in the development of their activities; and cross-border interactions combining indifferently the two types of interactions mentioned above when they appear between actors of different nationalities or on a border area. 
3) Characterization of spatial and prospective demand around future trends, to specify other context elements in the analysis, for example, obstacles or opportunities for the sector in its development or its means of expression of the spatial demand (e.g. technological development, political aspects, structuring / seniority of the sector) or of a state of play of MSP reflections or approaches in the State concerned which leads to a lack of statements and positions on the subject.

The purpose of this study was to explore the factors influencing the development of sectors (structure of the sector, policies, interactions, context, etc.) and to characterize positioning strategy with respect to MSP in terms of spatial demands. With regard to the elements analyzed and the results achieved, we identify five main trends in spatial demand strategies:

- Defense strategy for "historically used" of the space, mainly concerns the fishing and yachting sector and it is explained by the historic use right of the maritime area associated with these sectors of activity.

- Spatial expansion strategy mainly concerns the marine renewable energy sector and applies, in particular, to the northern area of the OSPAR IV Marine Region.

- Strategy for maintaining authorized areas, mainly concerns the fields of shellfish farming and marine aggregates extraction. These two activities have in common the fact that they use the means of the concession of use on a marine or littoral space to access the resource.

- Activities with spatial implications not directly influenced by MSP, concerns the sectors of maritime transport and submarine cables, governed by conventions and international maritime law, the organization of commercial shipping and submarine cables should be relatively unaffected by the actions of MSP.

- Activities in decline due to the decarbonation of European countries, in the three member states of the SIMNORAT project, the hydrocarbon exploitation activity is non-existent or in decline.

The sectorial analysis of activities shows a great diversity of involvement in the claim for spatial demand, from the wait-and-see posture to a pro-active posture of demand for "dedicated areas", that could be explained in part by the different legal regimes that accompany the regulation of the activities, the level of appropriation of the space, the conditions of access to the resource the "historical" use rights for certain activities and the spatial characteristics (e.g. location, water depth, mobility, land-sea interactions). In this work, the analysis of the sectors structure could highlight the weight that can represent a well-structured sector in the consultations about MSP. MSP also presents an opportunity to communities to get involved in the effective management of the ecosystems around them ${ }^{53}$ acting as a local governance tool. For 
instance, the process of establishing and managing MPAs requires careful planning and sensitive management ${ }^{54}$ which allows the inclusive representation of stakeholders in the planning process.

\subsection{Stakeholders data analysis: Potential approaches for stakeholder engagement on MSP}

The approach adopted for stakeholder engagement in SIMNORAT consisted on the organization of multisectors participatory workshops, based on information collected during interviews of different stakeholders from the three countries. The aim was to involve stakeholders in cross-border discussions and to support the sharing and use of good practices for the stakeholder engagement process, in order to contribute to the better coherence of the MSP processes in the three countries. For the interviews phase, once the list of potential stakeholders to be interviewed was settled, the best method to contact them was by email and by phone call. A call is important in order to have direct contact with them and also to explain what the objective of the interview will be and how it fits into a specific process. A total of 47 interviews were conducted in the 5 sectors of activities concerned (Table 2): Administration, Fisheries and Aquaculture, Conservation, Maritime transport and ports, Tourism and leisure and more sectors of activities left to the discretion of each country. The topics in the semistructure interview were adapted to the needs of gathering information on the topic "future trends" and "spatial demands" among others, in coherence with the general analysis of the project. The textual analysis concluded with 1983 quotes selected, classified by topic, activity and country. Ten topics for analysis were identified: MSP perception, governance and stakeholder engagement, future trends, spatial demands, cross-border dimension, link with other policies, conservation, economic development, opportunities and expectations and constraints and concerns.

Table 2. Sector of activities taken into account

\begin{tabular}{|l|l|}
\multicolumn{1}{|c|}{$\begin{array}{c}\text { SECTORS OF } \\
\text { ACTIVITIES }\end{array}$} & Administrations in charge of maritime issues \\
\hline Administration & $\begin{array}{l}\text { Associations, NGOs and environmental administrations in charge of } \\
\text { environment }\end{array}$ \\
\hline Conservation & Administrations in charge of safety and national security \\
\hline Defense & $\begin{array}{l}\text { Private and public bodies and administrations in charge of marine } \\
\text { renewable energy, marine aggregate extraction, oil and gas extraction, } \\
\text { etc. }\end{array}$ \\
\hline $\begin{array}{l}\text { Fisheries and } \\
\text { Aquaculture }\end{array}$ & $\begin{array}{l}\text { Private and public bodies and administrations in charge of fisheries } \\
\text { and/or aquaculture }\end{array}$ \\
\hline Leisure and yachting & $\begin{array}{l}\text { Associations, sport federation, private and public bodies and } \\
\text { administrations in charge of sports and leisure }\end{array}$ \\
\hline $\begin{array}{l}\text { Maritime transport } \\
\text { and Ports }\end{array}$ & $\begin{array}{l}\text { Private and public bodies and administrations in charge of maritime } \\
\text { transport and ports, port managers and ship-owners }\end{array}$ \\
\hline
\end{tabular}


This mixed method has demonstrated to offer a good vision about stakeholders' expectations in the MSP process, facilitating their engagement in the process. Participatory workshops as a tool to involve stakeholders are a great opportunity to introduce them to the MSP purpose and process, and to listen to their voicing by the peer to peer exchange (across sectors and borders). This allowed identifying issues of interest for transboundary coordination in planning. The testing of serious games as a tool for stakeholder engagement in association with post-it/mapping workshops helped to show and to understand the complexity of MSP and to simulate negotiation situations.

One of the main results of this task was that all stakeholders acknowledge the need for flexible plans over time. From the economic sectors representatives' points of view, it is essential to integrate the technological development and the emergence of new activities. From the perspective of the environmental conservation and protection sector representatives, this flexibility is required to adapt management and conservation measures to the evolution of species and ecosystems with regard to the challenges of climate change. Finally, the integration of the land-sea interface is not sufficient or almost non-existent according to stakeholders, while many land-based activities have a significant impact on the marine environment, particularly for the quality of marine waters. Therefore, the creation of cross-border and inter-sectorial programs could make it possible to better take into account land-based marine pollution.

\section{Case Studies}

The SIMNORAT project includes two case studies in cross-border areas dedicated one to the cumulative effects assessment of anthropogenic pressures on the marine environment between SP and FR, in the Bay of Biscay.. This case study aimed to explore tools, methods and data to assess environmental effects of maritime uses in the context of MSP and transboundary issues. The other case study shared by PT and SP, supported a conceptual methodology to create and manage a cross-border Marine Protected Area (MPA) between both countries. In order to achieve this, the case study focused on the existing Spanish MPA of Galicia Bank and on the Vigo and Vasco da Gama Seamounts.

\subsection{Case Study Bay of Biscay: Mapping exposure risk of marine megafauna to concomitant pressures}

This case study focused in the development of a specific Cumulative Effect Assessment (CEA) method in the Bay of Biscay between France and Spain. Its aim was to implement a common methodology, between the two countries, regarding spatial and temporal environmental effects of maritime uses on key pelagic species. The choice to study marine mammals and seabirds as ecological components is due to their high mobility, which allows them to cover the entire case study area. Thus, these species are common for Spain and France, which share conservation interests and target the same species in their marine protected areas. This case was a good opportunity to 
analyze methods and technical questions regarding data, tools, spatial and temporal resolution, and allowed highlighting and ranking areas of probable overlapping between anthropogenic pressures and key marine communities, by:

- Producing maps of human activities and major pressures affecting marine mammals and seabirds; and

- Producing maps of the potential exposure risk to human pressures for marine mammals and seabirds;

The variables considered to develop the test were 1) Environmental values: marine mammals and seabirds; 2) Human activities: fisheries and maritime transport; and 3) Pressures: physical disturbance, underwater noise and marine litter.

The method used was the "CARPEDIEM" for CEA based on one matrix establishing relationships between human activities and pressures and another one matrix describing the ecological sensitivity of habitats to different pressures (Figure 6).

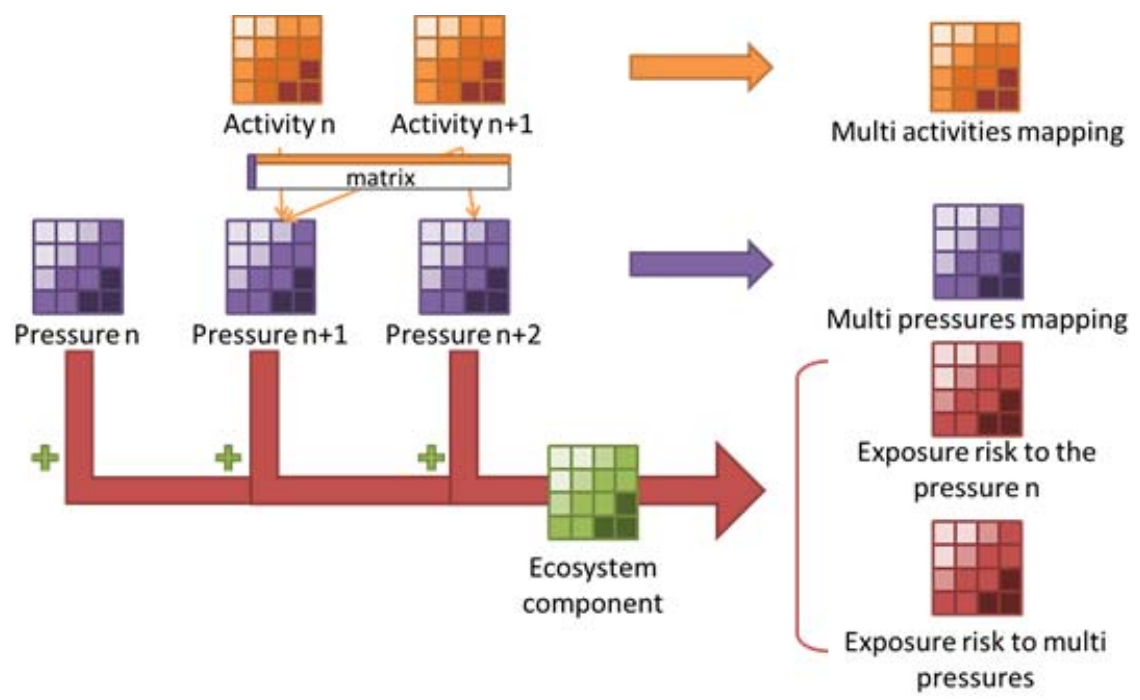

Figure 6. Overview of the four main steps of analysis. A: activity, P: pressure, E: Ecosystem component (marine mammal or seabird).

Finally, some challenges were identified in the development of this component. Identification and collection of existing / available data in both countries was very time consuming and not totally successful. Data was not available for the same periods of time in both countries or it was not possible to exchange. Therefore, data quality control and raw data edition to generate standardized and comparable datasets was a hard task to accomplish. Consequently, there was a need to assess differences based on application of this different data.

Also, this task laid the foundations for a relationship between project partners, a necessary first step in order to develop coherent planning and management approaches on both sides of the maritime borders ${ }^{63}$.

On the other hand, the ultimate goal of this task was to produce diagnosis useful to managers and decision-makers involved in MSP. Maps produced for this component 
are good illustrations of cross-border issues for conservation of marine biodiversity, showing that these methodologies play a key role in delivering EBM approaches into MSP63.

EDITED THE : 2018/12/10

Intensity of multi-pressures which can interact with great grey gulls - Simulation with Spanish and French data

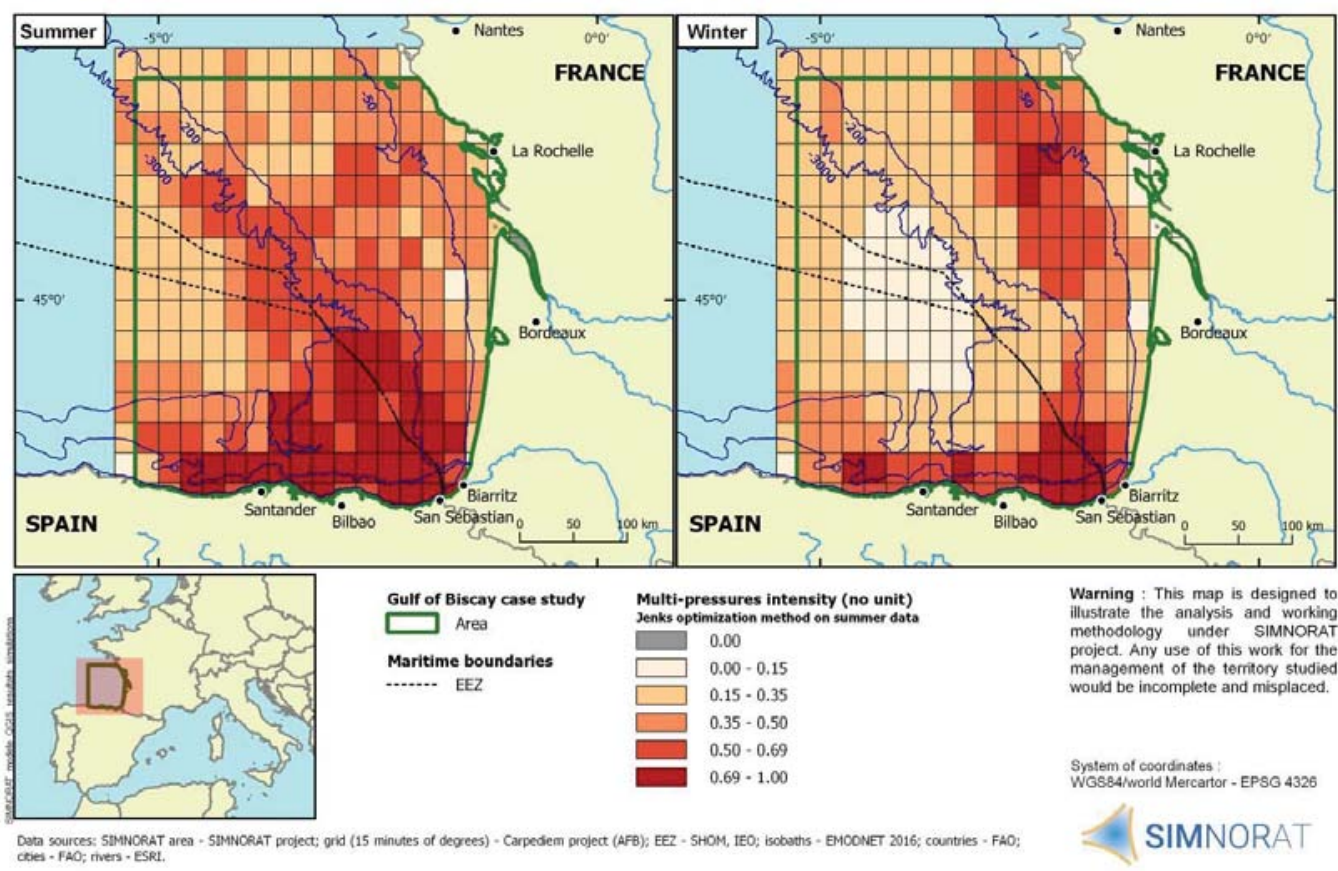

Figure 7. Intensity of multi-pressures that can interact with great grey gulls (simulation with Spanish and French datasets).

The main challenge faced by this case study was the collection and production of coherent datasets from both countries (e.i. in figure 7). However, the main interesting result was the networking of Spanish and French teams and the technical and methodological developments. Moreover, on the technical aspect, the pelagic component had not been studied yet in the cumulative effects assessment tool CARPEDIEM and progress could be achieved. This large-scale study is a good example and an opportunity to develop transboundary cooperation and projects between Spain and France in line with the recommendations of the MSFD and MSP Directives.

\subsection{Case Study Galicia Bank and Vigo and Vasco da Gama Seamounts: Cross-border Marine Protected Area management}

This case study was focused on the design of a legal and governance framework to implement a potential a cross-border MPA in the Northwest sector of Iberian Peninsula based in the EBA principle, addressing marine conservation the ecosystem level in the area between Spain and Portugal, including the Spanish Marine Protected Area of Galicia Bank and the Vigo and Vasco da Gama seamounts, located in the western limit of the geologic continental platform and on the northern limit of the Portuguese jurisdictional area and in the border of OSPAR regions IV and V. 
In order to consider the impacts from maritime activities, the case study was structured in two geographical scales (figure 8): (1) Analysis scale, covering the two conservation areas, the connectivity area between them and it extend to the coast to take into account all the pressures and activities that might represent a risk for conservation ${ }^{55}$; and (2) Management scale, formed by the two protected areas and the area between them.

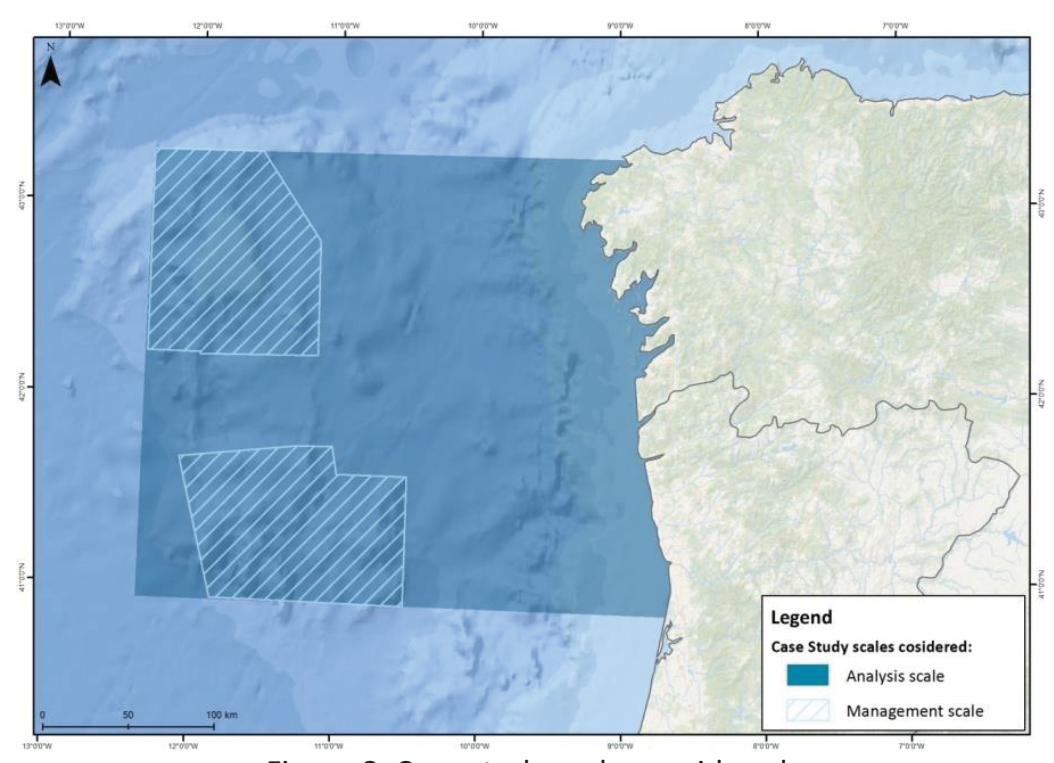

Figure 8. Case study scale considered.

The analysis implied the compilation of administrative, ecological, geological and maritime activities data in order to identify main challenges in transboundary MPA planning (jurisdiction disputes, accessing international data...), identification of knowledge gaps and synergies, conflicts between conservation and maritime activities, and stakeholder engagement in the case study area. In addition, the analysis of the governance framework in Spain and Portugal regarding marine conservation and MSP and the comparative analysis of Portuguese and Spanish maritime and coastal planning policies and management tools, was crucial to complete the case study.

This work evidenced there are differences in governance frameworks between Spain and Portugal concerning MSP and nature conservation, namely marine conservation responsibilities. The main, resides in the separation of competences, while Portugal has different organisms for MSP and marine nature conservation, in Spain competences are hold by the same institution ${ }^{55}$ (Figure 9). 

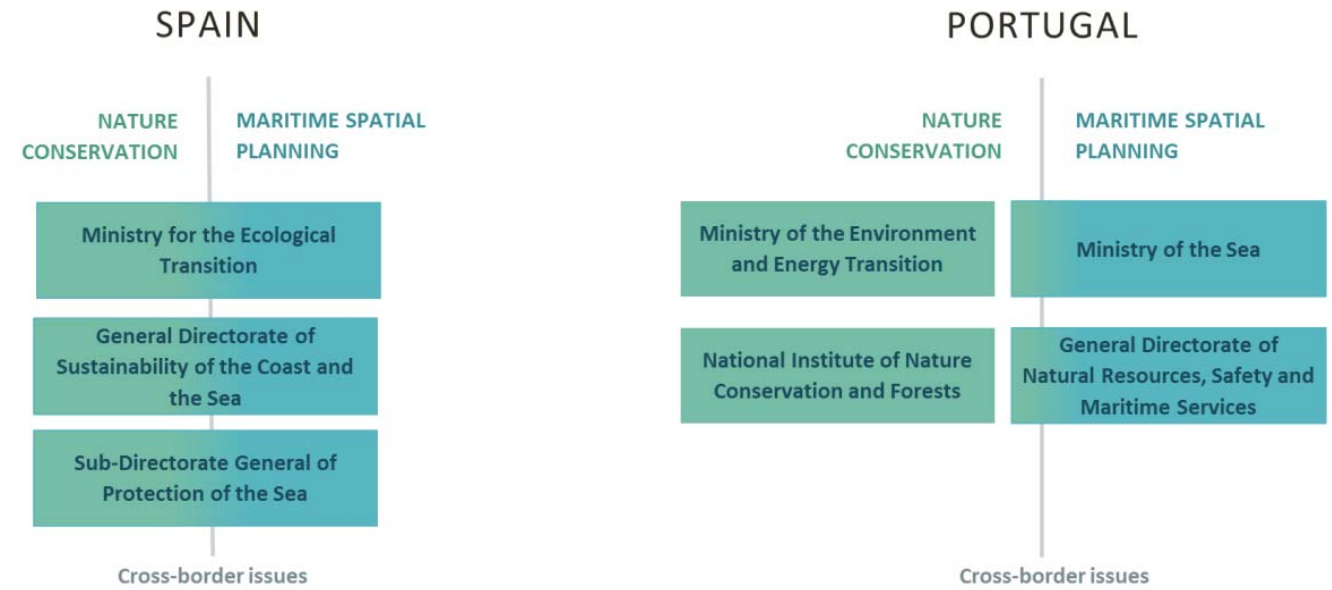

Figure 9. Governance framework of environmental conservation and MSP (Spain/Portugal).

A cross-border MPA management initiative must be based on the governance structure of both countries and formulated in such way that it is possible to, directly, or via corresponding management plans in either country, lay down legally effective recommendations or regulations ${ }^{55}$.

In this sense, stakeholder engagement is one of the main results of this case study, thus the workshop held between Spain and Portugal in the context of a transboundary MPA, about the cross-border dimension of MSP, implied the dialogue between maritime sectors of both countries to highlight the following:

a) Lack of strong conflicts between activities in the area to be protected as its ecological value is well demonstrated having little relevance for fishing,

b) Uncertain interest for mineral resources exploitation,

c) Low number of navigation routes crossing the area,

d) Renewable energy platforms are unfeasible at that distance from the coast,

e) Consensus on the convenience of data/information exchange platforms to optimize research investment and knowledge progress on the available resources of the area,

f) General agreement on the need of a stable communication mechanism between governments and stakeholders allowing the implementation of common governance mechanisms and management plans for this cross-border case study.

\section{Discussion}

Generally, EU requirements provide the basis for cross-border cooperation, although differences in administrative and governance structures make collaboration complex and differences in regulations may cause limitations in joint decision-making. Throughout the project's development, and in each of the objectives addressed, barriers have been identified where MS must continue to work together to overcome them, in order to carry out effective and coherent MSP processes. 
One of these barriers found is the definition of the geographical scale. The literature analysis laid the foundation for different management scales depending on: the size, density and characteristics of activities, their impacts, environmental vulnerability and existing governance structures ${ }^{24}$. In order to apply MSP according to the zone and the type of activity 33 it envisaged that "densely used or particularly vulnerable areas may require more prescriptive spatial plans whereas areas with low density of use may only require general management principles". In this case, when it is necessary to descend to a higher resolution scale, this must be accompanied by a higher resolution also in the spatial information or data, which is not always possible. The processing and standardization of data can be a significant burden for project developers ${ }^{1}$. Consequently, in the early stages of the process, it is essential to identify the general and specific objectives and the state of the available data to identify the scales needed to address the MSP process ${ }^{45,56}$. However, despite international recommendations to develop this approach in the implementation of MSP, plans and administrative boundaries often do not match the boundaries of ecosystem processes ${ }^{46,46}$, particularly in Europe, where marine jurisdictional boundaries are "so close and where many states are involved".

The concepts of integrated EBM seem to be often too broad, too abstract, and too complex to be operationally implemented ${ }^{2,4}$. Moreover, even if international instruments exist, EBM may represent legal problems in a cross-border context when the jurisdictional boundaries do not coincide with ecosystem boundaries and concerns several instruments and laws in different countries ${ }^{57}$. That is why ${ }^{46}$ suggest starting the analysis for a MSP implementation process with a bioregion scale. Thus, most of the work done on this topic recommends the implementation of regional, national and local maritime spatial planning ${ }^{15,33,47,58}$. A solution to this problem could be tackled with a nested approach ${ }^{28}$, where a distinction between two main scales is advised:

a) Analysis scale which comprise ecosystem boundaries and processes, been the broader and the one in which the definition of the strategic objectives will be based.

b) Management scale, an integral part of the planning boundaries, related to the definition of focus areas where operational objectives will be developed, depending on the peculiarities and the characteristics of each local area.

In this sense, the case study of the Cross-border MPA between Spain and Portugal fits the specific objectives of SIMNORAT project as a step forward in understanding current and potential future demands relevant to transboundary conservation areas, access to data and data-specific barriers to transboundary cooperation. Additionally, it considers potential options for transboundary cooperation in a context of a cross-border marine protected area including marine EBM approach ${ }^{55}$.

Regarding spatial data, there is a general agreement on the fact that MSP should be based on the best available, high quality and up-to-date spatial data ${ }^{59,60}$. Geographic information Systems (GIS) are used to aggregate individualize data and to allow planning options to be considered ${ }^{61}$. However, prior to the collection of data, planners must have very clear what type of information and data they will need, it is not a 
question of data ingestion, but rather it is necessary to carry out a previous exercise of identification of necessary data according to the objectives of the plan. For transboundary MSP, one of the barriers found was in the aspect of data organization, where there is a lack of harmonization and standardization in georeferenced information, ranging from different coordinate reference systems and formats to differences in indicators or measurement units, despite INSPIRE compliance, that has proved not always being enough depending on the resolution scale to work. The SPDP developed, was structured with a focus on INSPIRE web services (WMS, WFS, and WMTS). This brings several benefits as data is stored by the producer which avoids unnecessary duplication and lowers the administration processes. This protocol guarantees an access to the most up-to-date published data, not to duplicate the data maintenance work and it does not require storage of the information. Some opportunities have been found when defining scale and boundaries according to EBM, as the availability of some public databases regarding geology, habitats and oceanographic variables at supranational scale (e.g. EMODNET). However, there are still gaps in some types of data and when considering the definition of the "ecological boundaries" in the dynamic nature of some important ecological items (i.e. marine mammals).

A weakness identified by the three countries related to activities and uses data and spatial demands, is that some sectors are more organized and visible than others at administrative levels, which could cause imbalance between them. In addition, the difficulty in accessing confidential information of sectors, especially in the public domain, is a major barrier, since this even occurs between ministries. The main constraints found by each country have been data collection and mapping which are very time-consuming, especially in a cross-border context. Moreover, misbalance in data between sectors and/or countries could lead to wrong conclusions. The lack of scientific knowledge represents a gap in the full understanding of ecosystem services within cross-border regions and the benefits that those services represent to society that should be supported by governance systems.

The need to establish a plan in which present and future spatial demands are taken into account is evident; however, interactions that may arise between activities and environmental values suppose constraints or opportunities for the spatial development of a sector. This is one of the issues that arise when conducting the research on spatial demands. During this study and from the analysis of the information collected from the stakeholders, three types of interactions are thus studied as possible factors influencing the spatial demand: interactions between activities of different sectors or in the same sector (i.e. different fishing practices); the interactions between activities and environmental values where the parties felt as a constraint the limitations imposed in the development of their activities by environmental regulations; and cross-border interactions combining indifferently the two types of interactions mentioned above when they appear between actors of different nationalities or on a border area. These interactions are traditionally mainly approached from the angle of incompatibilities and thus recognized as factors constraining the spatial development of an activity. The analysis of the sectors in their spatial environment - in interaction with the other activities and the environmental 
conservation - carried out within the framework of SIMNORAT makes it possible to qualify this postulate:

- The supposedly negative interactions are not always real if we integrate well the multiple spatial dimensions of the maritime space and temporal dimension.

- Negative interactions are not necessarily linked to a conflict over the sharing of space and / or resource but on a lack of knowledge of the practices and rules of use of each activity.

- There are many positive interactions that can generate synergies and opportunities for co-development.

- Transboundary interactions may mainly involve near shore installations or resource competition (fishing).

Regarding conservation, the protection level provided on a MPA, have to be consistent with the conservation objectives and the existent pressures affecting the region, where a MPA is designated ${ }^{61}$. The strength of protection of a given designation is thus, specific to each country and specific to each site ${ }^{62}$ and in some cases, different conservation tools for designing MPA overlap (e.g. SPA and SCl sites of marine Natura 2000 network and OSPAR protected sites), especially in transboundary MPA's networks. However, this overlap of designations tools does not necessarily mean that a site is better protected than if there is only one designation. This also points at the need to bring coherence between management from various designations in the same area.

MSP goals will have to succeed in connecting and making the voices of all stakeholders, both economic and institutional, be heard in an integrated consultative process, before and after the implementation of the Directive by Member States. However, when, how, who they should been contacting?. The practice demonstrates that this requirement of the MSPD regarding stakeholder engagement is essential because, to guaranty the success of the plan, they must be an active part of it from the beginning to the end. On the basis of the results produced in the work done on improving stakeholder engagement, several questions for further investigation and testing have been brought out. For instance, partners in each country chose stakeholders to interview, so they can be different even in the same category, depending on the country, as occurred in Spain and Portugal where more of them came from the private sector. Which must be the scale for the stakeholders? Local, national and/or transnational? Which stakeholders and how to engage widely individuals besides representatives? How to communicate MSP to the general public to support stakeholder engagement? Are traditional training and brainstorming techniques sufficient?.

One of the important aspects highlighted by the project was that MSP generates many expectations between stakeholders and, in a cross-border context where sectorial problems are often common, the expectations for cross-border cooperation are stronger. Another important issue is the need to share and improve knowledge to create a solid basis that can support joint decision-making. During the workshops, 
many stakeholders manifested unawareness regarding background information or other sectors objectives.

The information collected during the interviews is a unique source allowing us to compare different opinions and to identify the needs of the sectors. Additionally, participatory workshops promote knowledge improvement and even the discovery of some activities proposed by the sectors (i.e. blue tourism compatible with artisanal fisheries). If these exchange forums become permanent, they could facilitate the identification of synergies and the improvement of cooperation between business sectors, but also between these sectors and the conservation dimension to implement efficient measures for environmental protection. In general, stakeholders understand and accept the EBAs a priority when it comes to making trade-offs between uses, the environment and maintenance of ecosystem services. However, doubts and distrust arise on how it should be implemented, as they stated that the same sectors are always the most affected (i.e. hydrocarbons exploitation, fishing, etc.) by environmental conservation measures.

The comparison between results of interviews and workshops shows that participatory workshops generated more proposals and solutions. Stakeholders are confronted with a specific case study (such as Bay of Biscay, the establishment of a transboundary marine protected area, etc.) and they know the specificities of these areas. They are therefore capable of offering concrete solutions to local problems as well as indicated lack of information in the areas.

In relation to serious games, these are not intended to collect information and data, in contrast to the two other methods, but to promote understanding of other points of view by the appropriation of other sectors stakes and roles. This game highlights the importance of discussions and the stakeholder's engagement in this kind of Directive in order to promote synergies and to limit the conflicts but especially to facilitate the social acceptability.

\section{Conclusions}

The intensification of economic activities in maritime and coastal areas in Europe, the need to prevent and adapt the coastline to climate change and the exploration and development of new maritime activities (marine renewable energies, blue biotechnologies), drive the need for new maritime and coastal planning solutions. The EU Directive on MSP is a first step towards sustainable and adaptive management but it has to be concerted and harmonized with the real needs of the territories. SIMNORAT has shown that in order to obtain better results, it is necessary to make collaborative efforts and to improve in certain aspects identified in the final conclusions:

- The use of MSFD monitoring program, indicators and surveillance, common for the three countries, could be an advantage for coherence. However, differences in the stages of MSFD implementation might threat the monitoring report momentum. Furthermore, MPAs are a governance tool that allows the 
participation of maritime sectors and civil society, serving, as a process, to foster public engagement in MSP. Therefore, coherence between MSFD and MSP implementation is a major perspective to address environmental, economical and social stakes, and so MPA objectives, through MSP.

- Improvement on coordination among administrations, both at national and international levels is needed, and competence distribution should be revisited to improve the coordination and cooperation between the departments that largely work independently of one another. A harmonized approach in the implementation of the Directives, including streamlining policy goals definition, as well as to improve the sharing of data. It is necessary to take both the horizontal coordination (between sectorial policies) and the vertical coordination (between different governance levels) into account and to develop common standards between neighbouring countries adopting a normative framework, as well as the cooperation and coordination between and among the various levels of decision-making;

- Considering the transboundary nature of marine resources and activities and the importance of cross-border collaboration between neighbouring states, regional sea conventions such as the OSPAR Convention, are efficient platforms to encourage, an facilitate a regional MSP approach, and to provide comprehensive regional marine perspectives in cross-border cooperation, which is critical to sustainable development. They are also important to promote Sea Basin Strategies, in this specific case the Atlantic Strategy and its Action Plan ${ }^{64}$, contributing to the success of the Integrated Maritime Policy and focused in the promotion of MSP as a tool.

- Management of maritime uses/activities and marine resources cannot be dissociated from the coastal zone processes, and vice versa. Many maritime uses need support installations on land. Some uses existing mostly on land (e.g., tourism, recreation, ports) expand their activities to the sea as well. These interactions need to be studied, in order to assess their individual and cumulative impacts and potential conflicts and synergies.

- The consequence of a mismatch between the ecological scale and the social/management scale, could lead to the failure of the plan. That is why the boundaries of analysis should not be limited to the boundaries of management, providing a nested approach solution. That also implies not a single consistent scale, but multiple scales adapted to the different stages of the process of implementation of MSP (analysis, stakeholders' participation, actions, etc.). It is the proper articulation of the scales throughout the process that will be the subject of a supported reflection.

- Spatial data must be addressed following common guides for MSP to overcome the interoperability issues encountered respect to data and methodologies, and the numerous sources should be centralized. It is necessary a common data model for MSP. Spatial data infrastructures based on Web Services in 
which data is not stored on local servers, but comes directly from the producers' SDI through a harvesting process, seems to be the best solution when approaching data issues at transboundary level.

- It is essential to improve and encourage the science-policy dialogue established to increase policy development based on scientific knowledge that is the basis of marine processes and to be able to guarantee the good environmental status of ecosystems and the services they provide related also in the application of MSFD.

- Great difficulties exist in identifying spatial demands despite some particular sectors (i.e. hydrocarbons exploration), as well as lack of strategic or sectorial planning in the sectors themselves. Likewise, another major obstacle is the difficulties in finding data regarding the organization of socioeconomic sectors, their governance, and in finding high quality and true information on sectorial trends (i.e. fisheries Vessel Monitoring System (VMS) data).

- A structured and organized sector is a factor facilitating the expression of demands because it allows being easily represented in the consultation bodies. The analysis of the vision of the activities representatives on the evolution trends of their sectors could provide elements of context to the expression of a particular spatial demand and to identify obstacles or opportunities conditioning its evolution (e.g. technological evolution, strong political will, regulatory framework, etc.).

- Cross-border workshops encourage sharing and improvement of knowledge, while discussions can promote synergies and cooperation between sectors themselves as well as encourage sustainable development, concerning environmental sensitivity. The use of role-playing is considered appropriate even if the game mechanics are simplified compared to reality in order to understand the complexity of the process and to make stakeholders empathized with the constraints of other maritime sectors and the difficulty of negotiating to mitigate conflicts. In this sense, many stakeholders consider that European funded projects, such as SIMNORAT are a good platform for this first approximation between stakeholders from different sectors and countries.

- The project highlighted the potential of a shared technical work, in terms of identifying scientific and technical teams across countries, identifying common needs, identifying opportunities to cover knowledge/methodological data gaps in neighbouring areas/countries, or exchanging and building common methods for common analyses for the purposes of answering to concrete administrative requirements or needs.

From the different conclusions of the project, some specific recommendations can be highlighted: 
- When choosing the competent authority to implement MSP and designing the process through pre-planning ${ }^{16}$, it is of great value to analyze the best way to align MSP and MSFD processes since the beginning. In the same way, it is important to establish, the proper strategy of coordination among different levels of administration (vertical and horizontally) to identify clear rules on how will the work flow be developed, easy to understand and follow for all the administrative stakeholders involved in the process.

- The first phases of analysis should always be approached at a bioregional scale as some natural process and activities impacts exceed jurisdictions. Transboundary projects are the best opportunity to create a first link between countries at technical level, which in the long term may lead to real cooperation at joint decision levels. This is why it is important that in these kinds of projects, institutions involved are the ones with real roles in the MSP processes in their countries.

- It is important to dedicate more effort in engaging those sectors that are underrepresented, as this lack of representation is sometimes due to their lack of organization but they might comprise a great socioeconomic value for the country or a particular region.

- Transboundary coordination and cooperation for MSP also could imply a better the dialogue between stakeholders from same activities of different countries that not have the chance to meet by other forums, for example, a particular sector that is only represented institutionally and not by its workers.

- A good stakeholder engagement strategy not only implies a huge number of events and people engaged but should concern more the way in which they are going to be engaged. Not all stakeholders benefit from the same kind of engagement. For instance, if there is a need for two sectors to understand each other, you may organize a workshop with role playing, but if information is required from a particular sector, an interview should be settled.

\section{Acknowledgements}

This work was supported by SIMNORAT EASME/EMFF/2018/1.2.1.5/SI2.806423; SIMATLANTIC EASME/EMFF/2015/1.2.1.3/03/SI2.742089; CESAM (UID/AMB/50017/2019); FCT/MCTES through national funds, and the co-funding by the FEDER, within the PT2020 Partnership Agreement and Compete 2020. We wish to express our thanks to all other members of the partner organizations involved in the project including AZTI and CETMAR. We would like to thank the reviewers for their valuable comments on the manuscript.

\section{References}

1 Jay, S., Alves, F.L., O'Mahony, C., Gomez, M., Rooney, A., Almodovar, M., Gee, K., de Vivero, J.L.S., Gonçalves, J.M.S., Fernandes, M. da Luz, Tello, O., Twomey, S., Prado, I., 
Fonseca, C., Bentes, L., Henriques, G., Campos, A., (2016). Transboundary dimensions of marine spatial planning: Fostering interjurisdictional relations and governance, Mar. Policy. 65: 85-96. doi:10.1016/j.marpol.2015.12.025.

2 Douvere, F., (2008). The importance of marine spatial planning in advancing ecosystem-based sea use management, Mar.Policy 32 (5) (2008)762-771.

3 European Commission, (2014). Directive of the European Parliament and of the Council of 23 July 2014, Establishing a Framework for Maritime Spatial Planning 2014/89/EU, Official Journal of the European Union, 2014.

${ }^{4}$ Queffelec, B., (2013). Planification de l'espace maritime et approche écosystémique en contexte transfrontalier : illustration franco-belge. VertigO. Hors-série 18.

5 Gilek, M. and Kerk, K., (2016). Governing Europe's Marine Environment. Europeanization of Regional Seas or Regionalization of EU Policies?, Chapter 3: Marine Governance: Institutional Capacity-building in a Multi-level Governance.

${ }^{6}$ ICZM, (2002). Recommendation of the European Parliament and of the Council of 30 May 2002 concerning the implementation of Integrated Coastal Zone Management in Europe. Official Journal L148, 06/06/2002 P.0024-0027. http://data.europa.eu/eli/reco/2002/413/oj

7 SIMNORAT: https://www.msp-platform.eu/projects/supporting-implementationmaritime-spatial-planning-north-atlantic-region

${ }^{8}$ Giret O., Morel C., Gimard A., Alloncle N., Le Moing E.,Quentric A., Quintela A., Lloret A., Lopes Alves F., Gomez Ballesteros M., Buceta J-L., Marques M., Plaza M., Silva A., Sousa L., (2019). EU Project Grant No.: EASME/EMFF/2015/1.2.1.3/03/SI2.742089. Initial Assessment. Supporting Implementation of Maritime Spatial Planning in the European Northern Atlantic (SIMNORAT). Cerema - Agence Française pour la Biodiversité. 91 pp. DOI: 10.5281/zenodo.2609165.

${ }^{9}$ Fernandes, M.L., Sousa, L.P., Quintela, A., Marques, M., Reis, J., Simão, A.P., Castro, A.T., Marques, J.M., Alves, F.L., (2020). Mapping the future: Pressures and impacts in the Portuguese maritime spatial planning, Sci. Total Environ. 715 (2020) 136863.

$10 \mathrm{HD}$, 92. COUNCIL DIRECTIVE 92/43/EEC of 21 May 1992 on the conservation of natural habitats and of wild fauna and flora.

11 Pınarbaşı, K., Galparsoro, I., Borja, V., Stelzenmüller, Á., Ehler, C.N., Gimpel, A., (2017). Decision support tools in marine spatial planning: Present applications, gaps and future perspectives, Mar. Policy. $83 \quad$ (2017) 83-91. doi:10.1016/j.marpol.2017.05.031. 
12 Ansong, J., Gissi, E., Calado, H., (2017). An approach to ecosystem-based management in Maritime spatial planning process. Ocean and Coastal Management, (141) 65-81.

${ }^{13}$ Domínguez-Tejo , E., Metternicht, G. and Johnston, E. and Hedge, L., (2016). Marine Spatial Planning advancing the Ecosystem-Based Approach to coastal zone management: A review. Marine Policy 72 (2016) 115-130.

${ }^{14}$ Stelzenmüller, V. H.O., Fock, A. ,Gimpel, H., Rambo, R., Diekmann, W.N., Probst, U., Callies, F., Bockelmann, H., Neumann, I., Kröncke, I., (2015). Quantitative environmental risk assessments in the context of marine spatial management: current approaches and some perspectives, ICES J. Mar. Sci.: J. du Cons. 72: 1022-1042.

${ }^{15}$ Coleman, H., Foley, M., Prahler, E., Armsby, M., Shillinger, G., (2011). Decision guide, Selecting decision support tools for marine spatial planning, Cent. Ocean Solut.

${ }^{16}$ Ehler, C. and Douvere, F., (2009). Marine Spatial Planning: a step-by-step approach toward ecosystem-based management. Intergovernmental Oceanographic Commission and Man and the Biosphere Programme. IOC Manual and Guides no. 53, ICAM Dossier no. 6. Paris: UNESCO. 2009.

\section{${ }^{17}$ https://www.msp-platform.eu/projects/transboundary-planning-european-atlantic}

18 Schultz-Zehden A., Gee K.,Scibior K., (2008). Handbook on Integrated Maritime Spatial Planning: http://www.baltseaplan.eu/

19 https://www.wur.nl/en/show/Maspnose-Maritime-spatial-planning-in-the-NorthSea.htm

\section{${ }^{20} \underline{\text { http://adriplan.eu }}$}

${ }^{21}$ Karppi, I., Kokkonen, M., Lähteenmäki-Smith, K., (2001). SWOT-analysis as a basis for regional strategies (Nordregio Working Paper). Stockholm: Nordregio. Retrieved from http://urn.kb.se/resolve?urn=urn:nbn:se:norden:org:diva-248

22 OSPAR, (1992). Convention for the Protection of the Marine Environment of the North-East Atlantic: https://www.ospar.org/convention

${ }^{23}$ UNCLOS, (1982). United Nations Convention on the Law of the Sea.

${ }^{24}$ Convention on Biological Diversity, (1992).

25 ESPOO Convention on environmental impact assessment in a transboundary context, (1991).

26 Burbridge, P.R., (1999). The Guiding Principles for a European ICZM Strategy. Towards a European Strategy forIntegrated Coastal Zone Management (ICZM). 
27 MSFD, (2008). DIRECTIVE 2008/56/EC OF THE EUROPEAN PARLIAMENT AND OF THE COUNCIL of 17 June 2008 establishing a framework for community action in the field of marine environmental policy (Marine Strategy Framework Directive).

${ }^{28}$ WFD, (2000). Directive 2000/60/EC of the European Parliament and of the Council of 23 October 2000 establishing a framework for Community action in the field of water policy.

29 Sousa, L.P., Dilasser, J., Ganne, M., Cervera Nuñez, C., Quintela, A., Marques, M., Silva, A., Alves, F.L., Sala, P., Campillos-Llanos, M., Gómez-Ballesteros, M., Alloncle, N., (2019). Land-Sea interaction and relationships with Integrated Coastal Zone management. EU Project Grant No.: EASME/EMFF/2015/1.2.1.3/03/SI2.742089. Supporting Implementation of Maritime Spatial Planning in the European Northern Atlantic (SIMNORAT). Cerema - UAVR. 17 pp. DOI: 10.5281/zenodo.2594720.

${ }^{30}$ Cumming, G. S., Cumming, D. H., \& Redman, C. L., (2006). Scale mismatches in socialecological systems: causes, consequences, and solutions. Ecology and Society, 11(1), 14.

31 Minang, P. A., Duguma, L. A., Alemagi, D., \& van Noordwijk, M., (2015). Scale considerations in landscape approaches. In Minang, P. A., van Noordwijk, M., Freeman, O. E., Mbow, C., de Leeuw, J., \& Catacutan, D. (Eds.) Climate-Smart Landscapes: Multifunctionality in Practice, 121-133. Nairobi, Kenya: World Agroforestry Centre (ICRAF).

32 Gilliland, P. M., and Laffoley, D., (2008). Key elements and steps in the process of developing ecosystem-based marine spatial planning. Marine Policy 32(5):787-796.

33 Flannery, W., O Cinneide, M., (2012). A roadmap for marine spatial planning: a critical examination of the European Commission's guiding principles based on their application in the Clyde MSP Pilot Project. Marine Policy 36, 265-271.

\section{${ }^{34}$ https://www.emodnet.eu/data}

35 Directive 2007/2/EC of the European Parliament and of the Council of 14 March 2007 establishing an Infrastructure for Spatial Information in the European Community (INSPIRE).

${ }^{36}$ Douvere, F., (2010). Marine spatial planning: Concepts. Current practice and linkages to other management approaches. Ghent University, Belgium.

\section{${ }^{37}$ http://www.maia-network.org}

38 Marine protected areas in the Atlantic arc - MAIA Project: https://www.maianetwork.org/homepage 
39 Abspoel, L. and Mayer, I., (2017). Maritime Spatial Planning Challenge Blue Development IOC UNESCO Edition Handbook (2017).

${ }^{40}$ Keijser, X., Ripken, M. and Warmelink, H., (2018). Maritime Spatial Planning - A Board Game for Stakeholder Involvement. In: Lukosh HK, Bekebrede G, Kortmann R (eds) Simulation Gaming. Applications for Sustainable Cities and Smart Infrastructures. ISAGA 2017. Lecture Notes in Computer Science. Springer International Publishing, pp 58-66.

${ }^{41}$ Keijser. X., Ripken. M. and Mayer, I., (2018). Stakeholder engagement in Maritime Spatial Planning: The efficacy of a serious game approach. Water (Switzerland) 10:116. doi: $10.3390 /$ w10060724.

${ }^{42}$ Carneiro, G., Thomas, H., Olsen, S., Benzaken, D., Fletcher, S., Méndez Roldán, S. and Damon Stanwell-Smith, D., (2017). Cross-border cooperation in Maritime Spatial Planning. EASME/ECFF/2014/1.3.1.8/SI2.717082. Study on international best practices for cross-border Maritime Spatial Planning. $110 \mathrm{pp}$.

${ }^{43}$ Cash, D. W., W. Adger, F. Berkes, P. Garden, L. Lebel, P. Olsson, L. Pritchard, and O. Young., (2006). Scale and cross-scale dynamics: governance and information in a multilevel world. Ecology and Society 11(2): 8. URL: http://www.ecologyandsociety.org/vol11/iss2/art8/

${ }^{44}$ Hein, L., Koppen, K., Groot, R. and van lerland, E., (2006). Spatial scales, stakeholders and the valuation of ecosystem services. Ecological Economics 57 (2006) 209-228.

45 Mills, M., Pressey, R., Weeks, R., Ban, N., Foale, S., (2010). A mismatch of scales: challenges in planning for implementation of marine protected areas in the Coral Triangle. Conserv. Lett., In review.

46 Ansong. J., Gissi. E., Calado. H., (2017). An approach to ecosystem based management in maritime spatial planning process. Ocean \& Coastal Management. Volume 141, Pages 65-81.

47 Maes, F., (2008). The international legal framework for marine spatial planning. Marine Policy 32, 797-810.

48 Dunstan, P., Bax, N., Dambacher, J., Hayes, K., Hedge, P., Smith, D., Smith. A., (2016). Using ecologically or biologically significant marine areas (EBSAs) to implement marine spatial planning. Ocean \& Coastal Management 121. 116-127.

${ }^{49}$ Dilasser, J., Ganne, M., Sala, P., Cervera-Nuñez, C., Sousa, L.P., Quintela, A., Marques, M., Silva, A., Alves, F.L., Campillos-Llanos, M., Gómez- Ballesteros, M. and Alloncle, N., (2019). Most appropriate geographical scale for MSP a national scale. EU Project Grant No.: EASME/ EMFF/2015/1.2.1.3/03/SI2.742089. Supporting Implementation of Maritime Spatial Planning in the European Northern Atlantic (SIMNORAT). Cerema UAVR. 27 pp. DOI: 10.5281/zenodo.2594737. 


\section{${ }^{50}$ https://www.maia-network.org/homepage}

${ }^{51}$ SIMNORAT Data Portal: https://simnorat.mspdata.eu/

52 SIMNORAT C1.3.3 Data and information requirements for MSP: Data management guidance document. https://zenodo.org/record/2597395\#.XjaSXyN7nIU

53 Douvere, (2015). UNESCO: World Heritage Marine Sites Managing effectively the world's most iconic Marine Protected Areas.

https://whc.unesco.org/document/137595

${ }^{54}$ Gubbay, (2004). Marine ProtectedAreas in the context of Marine Spatial Planning discussing the links. Report for WWF-UK:

http://assets.wwf.org.uk/downloads/mpas marinespacialplanning.pdf

${ }^{55}$ Marques, M. Quintela, A., Sousa, L., Alves, F. L.; Cervera-Núñez, C., Campillos-Llanos, M., Gómez-Ballesteros, M., Loret, A., Murciano, C.; Simão, A.P., Costa, A.C.; Marques, J. M., (2018). Case Study: Cross Border MPA Galacia Bank - Vigo and Vasco da Gama Seamounts. EU Project Grant No.: EASME/EMFF/2015/1.2.1.3/03/ SI2.742089. Supporting Implementation of Maritime Spatial Planning in the European Northern Atlantic (SIMNORAT). UAVR, DGRM, IEO, CEDEX 53pp.

56 Smith, N., Belpaeme, K., Maelfait, H., Vanhooren, S., Buchan, K., (2012). Why one size won't fit all: Marine Spatial Planning in Belgium, Dorset, unpublished document.

57 Wang, H., (2004). Ecosystem management and its application to large marine ecosystems: science, law and politics. Ocean Development and International Law 35 (1), 41-74.

58 Barbanti A., Campostrini P., Musco F., Sarretta A., Gissi E. (eds.), (2015). Developing a Maritime Spatial Plan for the Adriatic-Ionian Region. CNR-ISMAR, Venice, IT.

59 Commission of the European Communities (CEC), Roadmap for Maritime Spatial Planning: Achieving Common Principles in the EU, CEC, Brussels, 2008.

${ }^{60}$ Zaucha, J., (2012). Offshore spatial information: maritime spatial planning in Poland, Reg.Stud. 64 (4) (2012) 459-473.

61 Martin, K. St. and Hall-Arber, M., (2008). Themissinglayer: geo-technologies, communities, and implications for marine spatial planning, Mar.Policy 32 (5) (2008) 779-786.

62 MedPan, 2016:

http://d2ouvy59p0dg6k.cloudfront.net/downloads/medpan forum mpa 2016 bro chure a4 en web 1_.pdf 
63 Bliard, F., Dalleau, C., Quemmerais-Amice, F., Gimard, A., Alloncle, N., CampillosLlanos, M., Cervera-Núñez, C., Gómez-Ballesteros, M., Grassa, JM., Lloret, A., Murciano, C., Punzón, A., (2019). Bay of Biscay case study - Mapping exposure risk of marine megafauna to concomitant pressures. EU Project Grant No: EASME/EMFF/2015/1.2.1.3/03/SI2.742089. Supporting Implementation of Maritime Spatial Planning in the Northern European Atlantic (SIMNORAT). Deliverable Lead Partner. 75 pp. DOI: 10.5281/zenodo.2598150.

${ }^{64}$ Atlantic Strategy Action-Plan:

https://eur-lex.europa.eu/legalcontent/EN/TXT/PDF/?uri=CELEX:52013DC0279\&from=EN? 
1

2

3

4

5

9

10

11

12

13

14

15

16

17

18

19

20

21

22

23

24

25

26

27

28

29

30

31

32

33

34

35

36

37

38

39

40

41

42

43

44

45

46

47

48

49

50

51

52

53

54

55

56

57

58

59

60

61

62

63

64

65 
Transboundary cooperation and mechanisms for Maritime Spatial Planning implementation. SIMNORAT Project

Gómez-Ballesteros, M, Cervera - Núñez, C., Campillos-Llanos, M., Quintela, A., Sousa, L., Marques, M., L. Alves, F., Murciano, C., Alloncle, N., Sala, P., Lloret, A., Simão, A. P., Costa, A.C., Carval, D., Bailly, D., Nys, C., Sybill, H., Dilasser, J.

\section{Author Contributions}

Gómez-Ballesteros, M., Cervera-Núñez, C. and Campillos-Llanos, M. designed the article structure according to the tasks carried out during the project. They have been the Spanish researchers responsible for this work as they were involved in the general development of the project and its different tasks, having a more relevant role in the question of the scale, the identification of spatial demands, the stakeholder engagement task and the cross-border MPA case study. They have led the interpretation of the results. The ideas in the manuscript were developed through review of the deliverables of the project, group discussions and written up by them with contributions from all authors.

Quintela, A., Sousa, L., Marques, M. and Alves, F. contributed to the case study between Spain and Portugal: "Cross-border MPA - Galicia Bank and Vigo and Vasco da Gama seamounts" and also focused on harmonizing cumulative effects assessment as a step forward on their integration into transboundary Maritime Spatial Planning. Simão, A. P. and Costa, A.C carried out the overview of MSP implementation process in the definition of the case study area and scale in Portugal.

The data collection and information, analysis of data needs and gaps was carried out by Murciano, C. and Lloret and A. Carval, D. regarding human pressures and Gómez-Ballesteros, M., Cervera-Núñez, C., Campillos-Llanos, M. and Quintela, A. regarding the marine environment characterization.

Bailly, D., Nys, Sybill, H. C, Gómez-Ballesteros, M., Cervera - Núñez, C., Campillos-Llanos, M., Quintela, A., Sousa, L., Marques, M, Murciano, C., Lloret, A. and Alloncle, N. developed the stakeholders engagement data analysis.

Alloncle, N., Gómez-Ballesteros, M., Cervera-Núñez, C., Campillos-Llanos, M., Lloret, A., Murciano, C. and A.C., Carval have developed the Case Study between France and Spain in the Bay of Biscay: "Mapping exposure risk of marine megafauna to concomitant pressures."

Sala, P., Dilasser, J., Cervera-Núñez, C., Gómez-Ballesteros, M., Campillos-Llanos, M., Murciano, C., Lloret, A., Quintela, A., Sousa, L. and Marques, M. worked in the component of spatial demands identification. Sala, P. and Dilasser, J. coordinated the task while the other authors were contributing from their countries' perspectives. 